\title{
REVIEW
}

\section{Should paediatric units have bereavement support posts?}

\section{$P$ Jennings}

Arch Dis Child 2002;87:40-42

Eight bereavement support posts in paediatrics and maternity were established using the experience of the Child Bereavement Trust (CBT). Evaluation showed that staff welcomed the informal support and teaching for themselves, as well as support for families; $67 \%$ of staff who returned questionnaires felt care for bereaved families had improved as a result of the posts. Many felt that there had been a positive effect on staff retention and stress levels.

See end of article for authors' affiliations

Correspondence to: Mrs P Jennings, Walnut Tree Cottage, The Row, Lane End, Bucks HPI 4 3JR, UK; penny@ jenningsresearch.fsnet.co.uk

Accepted 12 March 2002

.................. n 1998 there were 9943 deaths recorded for babies (including stillbirths) and children 0-19 years in England and Wales. ${ }^{1}$ The grief that families feel in response to these deaths is a normal reaction to an abnormal event, but in some cases mothers who are not able to grieve fully at this time may be at increased risk of mental illness during subsequent pregnancies and following the birth of subsequent babies. ${ }^{23}$ The trauma may also have a negative impact on the parents' relationship, ${ }^{4-7}$ and there may be increased behavioural problems with children of parents who have lost a baby or child. ${ }^{78}$

Doctors and nurses in paediatric, neonatal, obstetric, and accident and emergency (A\&E) units may have feelings of guilt or failure when a child dies. In one study, only $6 \%$ of doctors in intensive care units had had any training in dealing with bereavement and grieving, and this was a major concern for the staff. ${ }^{9}$ Without training and support, this can lead to high levels of stress among staff who feel unprepared or unable to help families, and demoralised by any complaints.

The published literature concerning research on the efficacy of support posts is minimal. This qualitative study aimed to show how staff view a new bereavement support post in their clinical area in terms of improved care for families and guidance and support for themselves.

\section{ESTABLISHING NEW SUPPORT POSTS}

With a Department of Health grant, the Child Bereavement Trust (CBT) has developed eight bereavement support posts around the country, modelled on three well established posts. ${ }^{10}$ Seven of the appointees were nurses who had undertaken counselling courses (mostly at Diploma level) and one was a professional counsellor. The majority had been working in a clinical role and many kept this up part time, working in bereavement support for one to three days a week, with one full time. The average pay grade was G (equating to Administrative and Clerical Grade 6). A variety of acute areas were covered: paediatric and paediatric intensive care units, maternity, neonatal/special care baby units, antenatal/ postnatal and gynaecology wards, and A\&E. Many post holders also made visits in the community. A line manager who understood and valued the role was found to be critical in the evolution and success of new posts.

\section{METHODOLOGY}

The evaluation of these posts concentrated on changes that post holders had made, the effect on delivery of support and care for families, and the provision of individual counselling for parents. Levels of staff support and liaison were also assessed.

Seven recently appointed and the three well established post holders were interviewed (the eighth appointee only came into post after the field work had finished), plus at least one manager relevant to each post. The seven post holders (appointed between October 1998 and March 2000) completed a diary for one month to show how they spent their time. Questionnaires were placed in staff rooms where six of the post holders work, although this was not possible in the case of the seventh post holder. A total of 184 staff who felt their work was affected by the post completed and returned the questionnaire anonymously, including nurses, doctors, chaplains, and social workers.

\section{SUPPORT FOR FAMILIES}

Most post holders are informed of all baby/child deaths in the clinical areas they cover. They then offer parents an opportunity to meet and talk, leading to a formal counselling contract with a minority. An experienced counsellor has calculated that approximately one third of bereaved families go on to have some formal counselling. This number rises with the age of the child, though the need may not show itself for some months. ${ }^{11}$ Much time is spent giving families informal support, advice on practical matters such as funerals, and sometimes discussion with parents about the possibility of postmortem examination or organ donation.

Since the Alder Hey Inquiry, some senior doctors have suggested that it may be more appropriate for pathologists to obtain consent for postmortem examination or organ donation, but there is an argument for someone who already knows the family to be involved. ${ }^{12}$ Research into the follow up care of bereaved parents has shown that of 54 parents attending a bereavement clinic appointment, all except one saw the named

Abbreviations: A\&E, accident and emergency; $C B T$, Child Bereavement Trust 
neonatologist who had cared for their baby, with a neonatal nurse being present in 33\% of cases. ${ }^{13}$ Bereavement support post holders, especially if they have already spent some time with the parents, have been involved in such situations, either as part of the team at the initial meeting, or by a follow up meeting with parents.

Additionally, as will be described, they offer training and support to the staff involved and maintain close communication with staff concerning individual families.

Some families may meet the post holder before an expected death, thus helping both them and staff to be prepared for the death. Many post holders organise parent support groups and remembrance services, and help to establish good facilities for bereaved families, for example, a special room set apart from the clinical area where they can spend time with their child after they have died. Formal counselling may take place in the hospital or in the home, where other members of the family may also be seen. Detailed records are kept which may contribute towards an annual audit of the post holder's work.

\section{SUPPORT FOR STAFF}

The post holders only give formal support to a small percentage of bereaved families. There are no studies to chart the effects of increasingly appropriate care around the time of a child's death, but the experience of Jenni Thomas (founder and chief executive of CBT) during 17 years counselling, is that far fewer families who receive this care need formal counselling at a later date. ${ }^{14}$ The post holder may not be available when the baby or child dies, and it is, in any case, the responsibility and privilege of doctors, nurses, and midwives who have cared for the child, to continue to support and help the family after death has occurred. For example, neonatologists have described how the formidable task of talking to a family about the decision to remove life support often falls to the senior physician, in accordance with the parents' wishes. ${ }^{15}$ Providing this and other bereavement care well, such as the process of consent including that required for postmortem examination, can be stressful. It has been recognised that medical and nursing staff need adequate preparation and to know that there is someone they can talk to about such events who is knowledgeable and can give support. ${ }^{16}{ }^{17}$ Post holders have become known and trusted team members in the units where they work.

Consequently, although a few post holders offer formal counselling to Trust staff, the emphasis is on informal support and teaching. Out of 184 nurses, doctors, and other staff who completed a questionnaire, $37 \%$ said they had received support on an informal basis. For this to happen, the post holders have to be seen in the clinical unit, even if they do not have a clinical role. Not being a part of the clinical team can be an advantage, as described by one health professional: "She is someone that staff can turn to not working directly in the unit".

However, what begins as a member of staff's request for factual information may develop into a discussion about their feelings with regard to a stressful situation. This could not occur if the post holder were not a frequent, well known visitor to the unit. Post holders generally meet all new nurses and doctors to inform them, as part of their orientation, of how families can be cared for in bereavement and the part played by the post holder in helping both parents and staff. Some post holders run a regular bereavement forum, where staff discuss the death of any child since the last meeting and how bereavement support could be improved in the future. This can be one way of the team collaborating on new or adapted procedures, another important aspect of a bereavement support role. For example, a protocol may be developed for parents who wish to take their child home after they have died. ${ }^{18}$ Debriefing sessions have been used immediately following a particularly harrowing time to give all staff a chance to talk about how they felt. Some post holders have, or are about to, establish a staff support group.

The management of bereavement in A\&E units is known to be hampered by the inadequacy of training and facilities for a satisfactory way of dealing with this delicate and emotional issue.${ }^{19}$ Cooke said that "management of the bereaved relative or friend is one of the most difficult and delicate tasks performed in the A\&E department". ${ }^{20}$ A\&E units can be stressful for staff who sometimes have to offer compassionate care to bereaved families without the benefit of establishing any prior rapport with the family. ${ }^{21}$ An experienced A\&E nurse developed a scheme for staff to follow up families whose relative had died there..$^{22}$ This was possible through an annual training day provided by a bereavement support post holder, to train, prepare, and help staff in this new approach. The outcome has been satisfaction from both relatives and staff who experience a sense of completion. The scheme brought the originator a Clinical Practice and Management Award in 1999.

Teaching is also an important part of the post holder's role. This may involve the post holder arranging for experts to come and lead sessions with staff, such as a local funeral director or a consultant psychiatrist. Fifteen per cent of staff completing questionnaires in the present evaluation had attended a study day run in-house by CBT. Most of the post holders have also run their own workshops, on issues such as "How do we handle bad news?". Overall, $32 \%$ of staff said they had had some formal training in bereavement care through the post holder.

\section{OUTCOMES}

Research has shown that baby deaths can have a negative effect on mothers' wellbeing when next pregnant or in the postnatal period..$^{23}$ Ninety two of the 184 staff $(50 \%)$ who completed questionnaires indicated that their experience agreed with this. No study to date has looked at the level of complaints from parents and the relationship with bereavement support, but 74 staff $(40 \%)$ answered that they thought there had been a reduction in complaints from affected parents since the post holder began. A visual analogue scale was used to ascertain the extent to which staff thought the post had improved the quality of care offered to families who had lost a baby or child; 123 respondents $(67 \%)$ rated the post as 8 or more out of 10 .

Staff, through the questionnaires, reported significant changes and improvements in care stimulated by the new role, with $70 \%$ responding that the post holder's work had positively affected how they themselves look after families. In addition, $42 \%$ felt staff recruitment, retention, and/or sickness had been positively affected by the post holder's work. There were several comments in the staff questionnaires relating to this, for example:

- "Someone for staff to talk to"

- "A traumatic event may be so upsetting staff have left"

- "I am aware of staff who have decided to stay in post following support from the post holder".

\section{CONCLUSION}

This evaluation did not ask families to give their opinion as to the efficacy of the new posts. It is to be hoped that this may form part of a future study. However, it has shown that bereavement support is crucial in helping staff to give excellent care to families whose baby or child has died. Training gives them the relevant skills, and informal support on an individual or team basis reinforces good practice while reducing work related stress. Together with improved policies, this results in better care for families who subsequently should suffer less problems.

This is recognised by several hospitals who, as part of a new project, are creating bereavement support posts in their regional paediatric intensive care and A\&E units, with the 
expertise of CBT, and these appointees will particularly offer support to the siblings of children who die.

The Chief Medical Officer, in his recommendations following the Royal Liverpool Children's Inquiry, ${ }^{16}$ suggested the appointment of bereavement advisors to ensure all bereaved families are given opportunities to talk about what has happened, ask questions, and be informed about practical issues such as certification and postmortem examination. Families who subsequently are found to need formal counselling could be referred to an appropriate counsellor. NHS Trusts planning to follow the CMO recommendations for a bereavement advisor to fulfil a coordination role may contact the Child Bereavement Trust, who are supported by the Department of Health in the development of a two day training course.

However, although work in the Alder Hey hospital has shown that there is a need for such a person, ${ }^{23}$ it is the doctors and nurses who are with the family when a child dies and who need to be confident enough to listen to parents and to hear and respond to their needs. Indeed the success of such help is likely to depend on the confidence that each doctor or nurse has. ${ }^{7}$ This evaluation has shown that to help them achieve this, doctors and nurses can benefit from the ongoing guidance and support of a bereavement support expert, enabling them to look after families well while remaining positive about their role and confident in their job.

\section{ACKNOWLEDGEMENTS}

The posts evaluated here were part funded by a Department of Health Section 64 Grant. The Child Bereavement Trust established the posts and monitored their development. I thank all at CBT for their help with this project and the chief executive, Jenni Thomas, in particular for her vision which lies behind the work. I am also grateful to the new post holders and their managers for their time and goodwill.

\section{Author's affiliation}

P Jennings, The Child Bereavement Trust, Aston House, High Street, West Wycombe, High Wycombe HPl 4 3AG, UK

\section{REFERENCES}

1 Office for National Statistics. Series DH2: Mortality statistics: cause Series DH3: Mortality statistics: childhood, infant and perinatal. Health Statistics Quarterly 3.
2 Bourne S, Lewis E. Delayed psychological effects of perinatal deaths: the next pregnancy and the next generation. BMV 1984;289:147-8.

3 Hughes PM, Turton P, Evans CDH. Stillbirth as risk factor for depression and anxiety in the subsequent pregnancy: cohort study. BM 1999;318:1721-4

4 Cudmore L, Judd D. Traumatic loss and the couple. In: Clulow C, ed. Adult attachment and couple psychotherapy: the "secure base" in practice and research. Philadelphia, PA: Brunner-Routledge, 2001:152-70.

5 Schwab R. A child's death and divorce: dispelling the myth. Death Studies 1998;22:445-68.

6 Klas D. Marriage and divorce among bereaved parents in a self-help group. Omega 1996/97;17:237-49.

7 Woodward S, Pope A, Robson WJ, et al. Bereavement counselling after sudden infant death. BM 1985;290:363-5

8 Leon I. The invisible loss: impact of perinatal death on siblings. $J$ Psychosom Obstet Gynaecol 1986;5:14.

9 Granger CE, George C, Shelly MP. The management of bereavement on intensive care units. Intensive Care Med 1995;21:429-36.

10 Jennings $\mathbf{P}$. The first two years experience of child bereavement support posts. Evaluation of the Department of Health project. High Wycombe: The Child Bereavement Trust, 2001

11 Herkes B. Bereavement Counsellor, Directorate of Reproductive Medicine, Edinburgh. Personal communication, September 2001.

12 Jones SR. Who should gain informed consent for post mortems? British Journal of Midwifery 2001;9.

13 McHaffie HE, Laing IA, Lloyd DJ. Follow up care of bereaved parents after treatment withdrawal from newborns. Arch Dis Child Fetal Neonatal Ed 2001;84:F125-F128.

14 Thomas J. Maternity and Bereavement Facilitator, South Buckinghamshire NHS Trust. Personal communication, October 2001.

15 Jellinek MS, Catlin EA, Todres D, et al. Facing tragic decisions with parents in the neonatal intensive care unit: clinical perspectives. Pediatrics 1992;89:119-22.

16 RLC. The Royal Liverpool Children's Inquiry summary and recommendations. London: The Stationery Office, 2001 (HC12-1 ISBN 0102783012)

17 Bristol Royal Infirmary. The Bristol Royal Infirmary Inquiry summary. London: The Stationery Office, 2001 (ISBN 0101520735).

18 Thomas J. Supporting professionals when a baby or child dies. High Wycombe: The Child Bereavement Trust, 1999.

19 Cooke MW, Cooke HM, Glucksman E. Management of sudden bereavement in the accident and emergency department. BM 1992;304:1207-9.

20 Cooke MW. Care of the bereaved in the accident and emergency department. Care of the Critically III 1993;9:199-201.

21 Saines JC. Phenomenon of sudden death. Part 1. Accid Emerg Nurs 1997:5:164-71.

22 Saines JC. Unfinished business. Nurs Stand 1999;13:16-17.

23 Appleton R, Gibson B, Hey E. The loss of a baby at birth: the role of the bereavement officer. Br J Obstet Gynaecol 1993:100:51-4 